\title{
Comment on "A series of microRNA in the chromosome $14 q 32.2$ maternally imprinted region related to progression of non-alcoholic fatty liver disease in a mouse model"
}

\author{
Pietro Di Fazio ${ }^{1}$, Thaddeus Till Wissniowski ${ }^{2}$ \\ ${ }^{1}$ Department of Visceral, Thoracic and Vascular Surgery, Philipps University Marburg, 35043 Marburg, Germany. \\ ${ }^{2}$ Department of Gastroenterology, Philipps University Marburg, 35043 Marburg, Germany.
}

Corresponding Author:

Dr. Pietro Di Fazio, Department of Visceral, Thoracic and Vascular Surgery, Philipps University Marburg, Baldinger strasse, 35043 Marburg, Germany. E-mail: difazio@med.uni-marburg.de

Received: 06-06-2016, Accepted: 08-06-2016

Okamoto K, Koda M, Okamoto T, Onoyama T, Miyoshi K, Kishina M, Kato J, Tokunaga S, Sugihara TA, Hara Y, Hino K, Murawaki $Y$. A series of microRNA in the chromosome 14q32.2 maternally imprinted region related to progression of non-alcoholic fatty liver disease in a mouse model. PLoS One 2016;11:e0154676.

Non-alcoholic fatty liver disease (NAFLD) is a liver disease related to metabolic syndrome with rising socio-economic impact worldwide. NAFLD is defined by significant lipid deposition in hepatocytes that is unrelated to alcohol consumption. This high prevalence of liver disease occurs after a protracted inflammatory status caused by insulin resistance derived from high consumption of fructose-rich $\operatorname{goods}^{[1]}$ as shown by the multi-parallel hit theory. ${ }^{[2,3]}$

NAFLD is currently classified in simple steatosis (SS) and non alcoholic steatohepatitis (NASH). NAFLD is a benign condition without histological signs of inflammation and could be reversed by change of life style, recovering from hyperinsulinism and the metabolic syndrome. However, a protracted inflammation and elevated serum transaminases determine a severe stage of disease, so called $\mathrm{NASH}$, that affects the liver irreversibly leading to liver fibrosis, cirrhosis and cancer. ${ }^{[4]}$

MicroRNAs (miRNAs) represent one of the key regulators of epigenetic modifications. They are normally expressed in clusters and their mature forms are able to combine together with proteins and form the RNA-inducing silencing complex (RISC). ${ }^{[5]}$ Once the RISC is formed, miRNAs bind the high

\begin{tabular}{|l|c|}
\hline \multicolumn{3}{|c|}{ Access this article online } \\
\hline \multirow{2}{*}{ Website: } & Quick Response Code \\
\hline http://www.hrjournal.net/ & \\
DOI: &
\end{tabular}

affinity mature mRNAs forming a double RNA sequence. The duplex impedes the translational machinery and stabilizes the mRNA or promote its degradation.

So the exact role exerted by miRNAs is based on the inhibition of gene products expression. ${ }^{[6]}$ This fine regulatory mechanism is responsible of several cellular processes and can be altered in several diseases including NAFLD. ${ }^{[7-10]}$

Okamoto et al. ${ }^{[11]}$ present an outstanding study concerning a broad range analysis of miRNAs characterizing NAFLD mouse model and serum from patients affected by this disease.

They performed a microarray in order to identify the expression variation of miRNAs and their possible identification with NAFLD. The data obtained in the closest mouse model for NAFLD fatty liver shionogi ob/ ob characterized by mice bearing a spontaneous obesity mutation of the leptin gene (Lepob, commonly known as ob) were processed for similarity with human expressed miRNAs.

Interestingly, analysis of similarity conservation of miRNAs between rodent and human confirmed the expression of the same miRNAs in patient affected by SS and NASH. These miRNAs were identified at the maternally imprinted region (mat) of the chromosome $14 \mathrm{q} 32.2$.

Seven miRNAs were identified as markers for NAFLD, especially for NASH, all belonging to the Dlk1-Dio3 mat cluster.

This is an open access article distributed under the terms of the Creative Commons Attribution-NonCommercial-ShareAlike 3.0 License, which allows others to remix, tweak, and build upon the worknon-commercially, as long as the author is credited and the new creations are licensed under the identical terms.

For reprints contact: service@oaepublish.com

How to cite this article: Di Fazio P, Wissniowski TT. Comment on "A series of microRNA in the chromosome $14 q 32.2$ maternally imprinted region related to progression of non-alcoholic fatty liver disease in a mouse model". Hepatoma Res 2016;2:205-6. 
Here, we highlight the importance that have these miRNAs as repressor of factors coordinating the cell fate by triggering pro-death mechanisms e.g. apoptosis and autophagy.

In particular, the authors reported that AMP-activated protein kinase (AMPK) is a target of the majority of the identified miRNAs. AMPK is responsible of metabolic processes as mentioned by the authors, thus conferring it also a key role during autophagy. ${ }^{[12]}$ In particular, AMPK is responsible of ULK1 (serine/threonine-protein kinase) phosphorylation with consequent mammalian target of rapamycin complex (mTORC) inhibition and autophagy activation during nutrient starvation. ${ }^{[12]}$ Autophagy represents a fine regulated mechanism to overcome cellular stress and promote cell death in case of protracted cellular stress. It has been shown that its modulation can be a promising target for cancer therapy in liver cancer. ${ }^{[13]}$ The expression of miRNAs repressing autophagy regulators like AMPK could highlight the variations occurring at epigenetic level conferring to cells an altered metabolism that irreversibly modifies the liver cells and tissue. These alterations could be responsible to trigger further pathological cellular features leading to cirrhosis and furthermore liver carcinogenesis. ${ }^{[14,15]}$ For this reason it will be interesting to further focus on the expression of the miRNAs localized at mat $14 q 32.2$ in patients affected by cirrhosis and liver cancer, as it has been already shown for other miRNAs in liver cancer cells and thyroid cancer. ${ }^{[16-18]}$ The miRNAs discovered in this study can represent valid targets for the diagnosis of NAFLD and could be furthermore adopted as biomarkers for patients affected by cirrhosis and liver cancer.

Finally, inhibition of mTORC by the use of biguanides (metformin), ${ }^{[19]}$ a well known mTOR inhibitors currently used for the treatment of type 2 diabetes, ${ }^{[20]}$ could represent a therapeutic target for $\mathrm{NASH}^{[21]}$ in a translational setting defining mTORC as a major target of NASH related miRNA.

\section{Financial support and sponsorship} Nil.

\section{Conflicts of interest}

There are no conflicts of interest.

\section{REFERENCES}

1. Basaranoglu M, Basaranoglu G, Sabuncu T, Senturk H. Fructose as a key player in the development of fatty liver disease. World J Gastroenterol 2013;19:1166-72.

2. Day CP, James OF. Steatohepatitis: a tale of two "hits"? Gastroenterology 1998;114:842-5.

3. Tilg H, Moschen AR. Evolution of inflammation in nonalcoholic fatty liver disease: the multiple parallel hits hypothesis. Hepatology 2010;52:1836-46.

4. Sanyal AJ, Brunt EM, Kleiner DE, Kowdley KV, Chalasani N, Lavine
JE, Ratziu V, McCullough A. Endpoints and clinical trial design for nonalcoholic steatohepatitis. Hepatology 2011;54:344-53.

5. Bartel DP. MicroRNAs: genomics, biogenesis, mechanism, and function. Cell 2004;116:281-97.

6. Gregory RI, Chendrimada TP, Cooch N, Shiekhattar R. Human RISC couples microRNA biogenesis and posttranscriptional gene silencing. Cell 2005;123:631-40.

7. Cheung O, Puri P, Eicken C, Contos MJ, Mirshahi F, Maher JW, Kellum JM, Min H, Luketic VA, Sanyal AJ. Nonalcoholic steatohepatitis is associated with altered hepatic microRNA expression. Hepatology 2008;48:1810-20.

8. Pogribny IP, Starlard-Davenport A, Tryndyak VP, Han T, Ross SA, Rusyn I, Beland FA. Difference in expression of hepatic microRNAs miR-29c, miR-34a, miR-155, and miR-200b is associated with strainspecific susceptibility to dietary nonalcoholic steatohepatitis in mice. $L a b$ Invest 2010;90:1437-46.

9. Alisi A, Da Sacco L, Bruscalupi G, Piemonte F, Panera N, De Vito R, Leoni S, Bottazzo GF, Masotti A, Nobili V. Mirnome analysis reveals novel molecular determinants in the pathogenesis of diet-induced nonalcoholic fatty liver disease. Lab Invest 2011;91:283-93.

10. Choi SE, Fu T, Seok S, Kim DH, Yu E, Lee KW, Kang Y, Li X, Kemper B, Kemper JK. Elevated microRNA-34a in obesity reduces NAD+ levels and SIRT1 activity by directly targeting NAMPT. Aging Cell 2013;12:1062-72.

11. Okamoto K, Koda M, Okamoto T, Onoyama T, Miyoshi K, Kishina M, Kato J, Tokunaga S, Sugihara TA, Hara Y, Hino K, Murawaki Y. A series of microrna in the chromosome 14q32.2 maternally imprinted region related to progression of non-alcoholic fatty liver disease in a mouse model. PLoS One 2016;11:e154676.

12. Ha J, Guan KL, Kim J. AMPK and autophagy in glucose/glycogen metabolism. Mol Aspects Med 2015;46:46-62.

13. Di Fazio P, Waldegger P, Jabari S, Lingelbach S, Montalbano R, Ocker M, Slater EP, Bartsch DK, Illig R, Neureiter D, Wissniowski TT. Autophagyrelated cell death by pan-histone deacetylase inhibition in liver cancer. Oncotarget 2016; doi: 10.18632/oncotarget.8585.

14. Mahgoub A, Steer CJ. MicroRNAs in the evaluation and potential treatment of liver diseases. J Clin Med 2016;5:52.

15. Kanda M, Sugimoto H, Kodera Y. Genetic and epigenetic aspects of initiation and progression of hepatocellular carcinoma. World $J$ Gastroenterol 2015;21:10584-97.

16. Damanakis AI, Eckhardt S, Wunderlich A, Roth S, Wissniowski TT, Bartsch DK, Di Fazio P. MicroRNAs let7 expression in thyroid cancer: correlation with their deputed targets HMGA2 and SLC5A5. $J$ Cancer Res Clin Oncol 2016;142:1213-20.

17. Henrici A, Montalbano R, Neureiter D, Krause M, Stiewe T, Slater EP, Quint K, Ocker M, Di Fazio P. The pan-deacetylase inhibitor panobinostat suppresses the expression of oncogenic miRNAs in hepatocellular carcinoma cell lines. Mol Carcinog 2015;54:585-97.

18. Di Fazio P, Montalbano R, Neureiter D, Alinger B, Schmidt A, Merkel AL, Quint K, Ocker M. Downregulation of HMGA2 by the pandeacetylase inhibitor panobinostat is dependent on hsa-let-7b expression in liver cancer cell lines. Exp Cell Res 2012;318:1832-43.

19. Khawaja MR, Nick AM, Madhusudanannair V, Fu S, Hong D, McQuinn LM, Ng CS, Piha-Paul SA, Janku F, Subbiah V, Tsimberidou A, Karp D, Meric-Bernstam F, Lu KH, Naing A. Phase I dose escalation study of temsirolimus in combination with metformin in patients with advanced/ refractory cancers. Cancer Chemother Pharmacol 2016;77:973-7.

20. Provinciali N, Lazzeroni M, Cazzaniga M, Gorlero F, Dunn BK, DeCensi A. Metformin: risk-benefit profile with a focus on cancer. Expert Opin Drug Saf 2015;14:1573-85.

21. Xu H, Zhou Y, Liu YX, Ping J, Shou QY, Chen FM, Ruo R. Metformin improves hepatic IRS2/PI3K/Akt signaling in insulin resistant rats of NASH and cirrhosis. J Endocrinol 2016;229:133-44. 